University of Nebraska - Lincoln

DigitalCommons@University of Nebraska - Lincoln

Publications, Agencies and Staff of the U.S.

Department of Commerce

U.S. Department of Commerce

2010

Dreissenid mussels are not a "dead end" in Great Lakes food

webs

Charles P. Madenjian

U.S. Geological Survey, cmadenjian@usgs.gov

Steven A. Pothoven

National Oceanic and Atomospheric Administration, steve.pothoven@noaa.gov

Philip J. Schneeberger

Michigan Department of Natural Resources, schneebp@michigan.gov

Mark P. Ebener

Chippewa Ottawa Resource Authority, mebener@lighthouse.net

Lloyd C. Mohr

Ontario Ministry of Natural Resources, lloyd.mohr@mnr.gov.on.ca

See next page for additional authors

Follow this and additional works at: https://digitalcommons.unl.edu/usdeptcommercepub

Part of the Environmental Sciences Commons

Madenjian, Charles P.; Pothoven, Steven A.; Schneeberger, Philip J.; Ebener, Mark P.; Mohr, Lloyd C.;

Nalepa, Thomas F.; and Bence, James R., "Dreissenid mussels are not a "dead end" in Great Lakes food webs" (2010). Publications, Agencies and Staff of the U.S. Department of Commerce. 402.

https://digitalcommons.unl.edu/usdeptcommercepub/402

This Article is brought to you for free and open access by the U.S. Department of Commerce at DigitalCommons@University of Nebraska - Lincoln. It has been accepted for inclusion in Publications, Agencies and Staff of the U.S. Department of Commerce by an authorized administrator of DigitalCommons@University of Nebraska - Lincoln. 


\section{Authors}

Charles P. Madenjian, Steven A. Pothoven, Philip J. Schneeberger, Mark P. Ebener, Lloyd C. Mohr, Thomas F. Nalepa, and James R. Bence 


\title{
Dreissenid mussels are not a "dead end" in Great Lakes food webs
}

\author{
Charles P. Madenjian ${ }^{\mathrm{a}, *}$, Steven A. Pothoven ${ }^{\mathrm{b}}$, Philip J. Schneeberger ${ }^{\mathrm{c}}$, Mark P. Ebener ${ }^{\mathrm{d}}$, Lloyd C. Mohr ${ }^{\mathrm{e}}$, \\ Thomas F. Nalepa ${ }^{\text {f }}$, James R. Bence ${ }^{\mathrm{g}}$ \\ a U. S. Geological Survey, Great Lakes Science Center, 1451 Green Road, Ann Arbor, MI 48105, USA \\ ${ }^{\mathrm{b}}$ National Oceanic and Atmospheric Administration, Great Lakes Environmental Research Laboratory, 1431 Beach Street, Muskegon, MI 49441, USA \\ c Michigan Department of Natural Resources, Marquette Fisheries Research Station, 484 Cherry Creek Road, Marquette, MI 49855, USA \\ d Chippewa Ottawa Resource Authority, Inter-Tribal Fisheries and Assessment Program, 179 West Three Mile Road, Sault Ste. Marie, MI 49783, USA \\ e Ontario Ministry of Natural Resources, Upper Lakes Management Unit, 1450 Seventh Avenue East, Owen Sound, Ontario, Canada N4K $2 Z 1$ \\ ${ }^{\mathrm{f}}$ National Oceanic and Atmospheric Administration, Great Lakes Environmental Research Laboratory, 2205 Commonwealth Boulevard, Ann Arbor, MI 48105, USA \\ g Michigan State University, Department of Fisheries and Wildlife, 13 Natural Resources Building, East Lansing, MI 48824, USA
}

\section{A R T I C L E I N F O}

\section{Article history:}

Received 16 December 2008

Accepted 9 April 2009

Communicated by Trent M. Sutton

\section{Index words:}

Bioenergetics modeling

Dreissenid mussels

Invasive species

Lake whitefish

Population modeling

Predation

\begin{abstract}
A B S T R A C T
Dreissenid mussels have been regarded as a "dead end" in Great Lakes food webs because the degree of predation on dreissenid mussels, on a lakewide basis, is believed to be low. Waterfowl predation on dreissenid mussels in the Great Lakes has primarily been confined to bays, and therefore its effects on the dreissenid mussel population have been localized rather than operating on a lakewide level. Based on results from a previous study, annual consumption of dreissenid mussels by the round goby (Neogobius melanostomus) population in central Lake Erie averaged only 6 kilotonnes (kt; $1 \mathrm{kt}=$ one thousand metric tons) during 1995-2002. In contrast, our coupling of lake whitefish (Coregonus clupeaformis) population models with a lake whitefish bioenergetics model revealed that lake whitefish populations in Lakes Michigan and Huron consumed 109 and 820 kt, respectively, of dreissenid mussels each year. Our results indicated that lake whitefish can be an important predator on dreissenid mussels in the Great Lakes, and that dreissenid mussels do not represent a "dead end" in Great Lakes food webs. The Lake Michigan dreissenid mussel population has been estimated to be growing more than three times faster than the Lake Huron dreissenid mussel population during the 2000s. One plausible explanation for the higher population growth rate in Lake Michigan would be the substantially higher predation rate by lake whitefish on dreissenid mussels in Lake Huron.
\end{abstract}

Published by Elsevier B.V.

\section{Introduction}

Dreissenid mussels invaded the Laurentian Great Lakes from the late 1980s through the 1990s (Nalepa et al., 2005). The dreissenid mussel invasions in Lakes Michigan, Huron, Erie, and Ontario have been linked to declines in the abundance of the amphipod Diporeia, although the mechanism by which the mussels are negatively affecting Diporeia abundance remains unidentified. Decreases in lake whitefish (Coregonus clupeaformis) condition and growth in Lakes Michigan, Huron, and Ontario have been attributed, at least in part, to the Diporeia abundance declines (Nalepa et al., 2005). In addition, the dreissenid mussel invasions of the Great Lakes have been associated with other changes in the benthic macroinvertebrate community structure as well as changes in the zooplankton community (Haynes

\footnotetext{
* Corresponding author. Tel.: +1 7342147259.

E-mail addresses: cmadenjian@usgs.gov (C.P. Madenjian), steve.pothoven@noaa.gov (S.A. Pothoven), schneebp@michigan.gov (P.J. Schneeberger), mebener@lighthouse.net (M.P. Ebener), lloyd.mohr@mnr.gov.on.ca (L.C. Mohr), thomas.nalepa@noaa.gov (T.F. Nalepa), bence@msu.edu (J.R. Bence).
}

et al., 1999; Johannsson et al., 2000). Further, Hecky et al. (2004) proposed that dreissenid mussels act as ecosystem engineers responsible for a nearshore phosphorus shunt. In their conceptual model, dreissenid mussels redirected energy and nutrients such as phosphorus to the nearshore zone, while offshore phosphorus remained low.

Several ecologists have regarded dreissenid mussels as a "dead end" in Great Lakes food webs because the degree of predation on dreissenid mussels, on a lakewide basis, is believed to be limited (Arney and Grubbs 2001; Environment Canada and U. S. Environmental Protection Agency 2003). Diving ducks, such as the greater scaup (Aythya marila), lesser scaup (Aythya affinis), and white-winged scoter (Melanitta deglandi), do feed on dreissenid mussels in bays and selected nearshore areas of Lake Erie during the fall, but their predation effects are quite localized (Mitchell et al., 2000). Further, this predation effect was found to be temporary, because the dreissenid mussel population had the ability to recover from the predation by the following fall (Mitchell et al., 2000). Bunnell et al. (2005) used bioenergetics modeling to estimate annual consumption of dreissenid mussels by the round goby (Neogobius melanostomus) population in the central basin of Lake Erie during 1995-2002. Because annual consumption averaged only 6 kilotonnes $(\mathrm{kt} ; 1 \mathrm{kt}=$ one thousand 
metric tons), which was more than 100 times lower than the standing stock biomass estimate of dreissenid mussels in central Lake Erie, Bunnell et al. (2005) concluded that round gobies were having a minimal effect on dreissenid mussel population dynamics in central Lake Erie.

During the 2000s in Lakes Michigan and Huron, dreissenid mussels have become an important component of lake whitefish diet, representing up to $80 \%$ of the diet for some age groups (Pothoven and Madenjian 2008). Lake whitefish is one of the most abundant benthivores in Lakes Michigan and Huron (Nalepa et al., 2005). Therefore, we may expect a relatively strong trophic link between dreissenid mussels and lake whitefish within these two lake ecosystems.

As a consequence of the 2000 Consent Decree between the Chippewa Ottawa Resource Authority and the State of Michigan, an opportunity now exists to estimate the degree of predation on dreissenid mussels by lake whitefish populations in Lakes Michigan and Huron. One of the actions taken under the 2000 Consent Decree was to begin applying statistical catch-at-age (SCAA) models to the lake whitefish populations in both lakes in order to better manage the fisheries (Ebener et al. 2005). Application of the SCAA models requires an intensive, multiagency effort each year to summarize the various types of fishery data for each of the management units and then integrate these data into the SCAA models to generate estimates of population sizes and biomasses by age, age-specific total mortalities, and age-specific fishing mortalities. A bioenergetics model for lake whitefish has been evaluated, and then modified to improve the accuracy of predictions of food consumption (Madenjian et al., 2006).
In sum, the data and appropriate modeling tools needed to estimate consumption of dreissenid mussels by lake whitefish populations in Lakes Michigan and Huron are now available.

The primary objective of this study was to estimate annual consumption of dreissenid mussels by lake whitefish populations in Lakes Michigan and Huron. The secondary objective of this study was to discuss the potential for lake whitefish predation to slow the population growth rate of dreissenid mussels.

\section{Methods}

For each of the lake whitefish management units in Lakes Michigan and Huron, an SCAA model was fitted to lake whitefish fishery data, provided that the fishery data were sufficient for model application (Ebener et al., 2005). The lake whitefish management units in Lake Michigan with sufficient data for SCAA model applications included WFM-00, WFM-01, WFM-02, WFM-03, WFM-04, WFM-05, WFM-06, and WFM-08 (Fig. 1). The lake whitefish management units in Lake Huron with sufficient data for SCAA model applications included WFH-01, WFH-02, WFH-04, WFH-05, QMA 4-2, QMA 4-3, QMA 4-4, QMA 4-5, QMA 4-7, QMA 5-8, QMA 5-9, and QMA 6-1. Estimates of population sizes by age and age-specific mortalities were generated from each SCAA model application, and growth trajectories were estimated from the commercial catch and fishery-independent data. Each SCAA model application yielded population size estimates and mortality estimates for each of years of fishery data included in the model application. Diet data for lake whitefish from Lakes Michigan and Huron were available for the 1998-2005 and 2002-2004 periods,

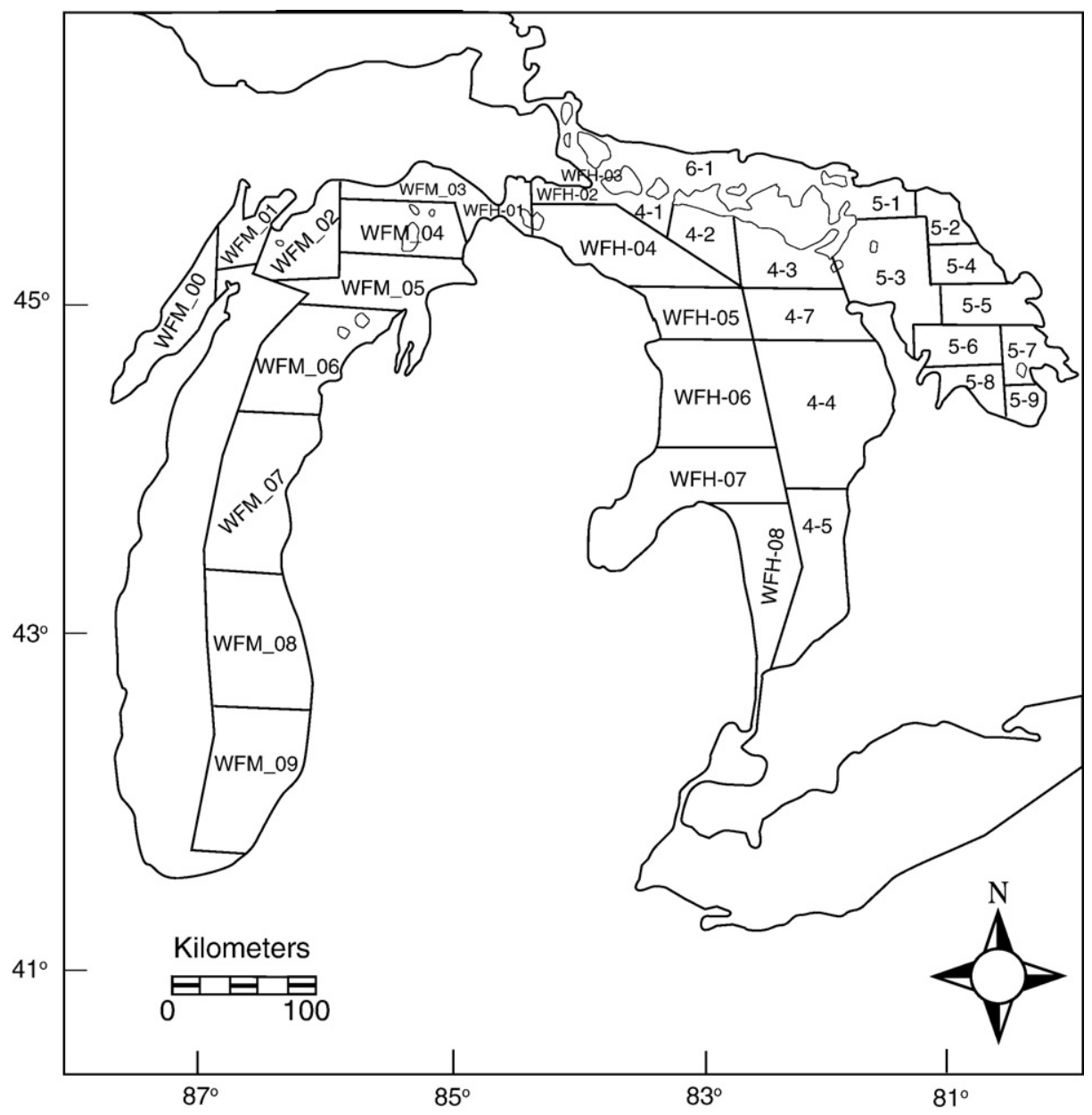

Fig. 1. Map showing the lake whitefish management units in Lakes Michigan and Huron. The QMA management units were designated by an integer followed by a hyphen and a second integer. 
respectively. To match lake whitefish population parameters to the available diet data, we determined the average population parameters over the abovementioned time periods for each of the management units in the two lakes. We then used the average population parameters to estimate annual consumption by the lake whitefish. Some sections of each lake were not included in any of the management units that were modeled in our study (Fig. 1).

To estimate annual consumption by lake whitefish, we used the modified version of the Wisconsin lake whitefish bioenergetics model (Madenjian et al., 2006). Lake whitefish diet composition data, lake whitefish energy densities, energy densities of lake whitefish prey, and water temperature regimes experienced by lake whitefish were taken from our previous studies on lake whitefish feeding, growth, and energy density (Madenjian et al., 2006; Pothoven et al., 2006; Pothoven and Madenjian 2008). For each combination of management unit and lake whitefish age, the lake whitefish bioenergetics model was coupled with the pertinent lake whitefish population parameters to estimate annual consumption of dreissenid mussels. Our estimates of annual consumption of dreissenid mussels were expressed on a wet-weight basis and included dreissenid mussel shells.

For both Lake Michigan and Lake Huron, we summed the annual consumption estimates across all combinations of lake whitefish age and management unit. The sum was then multiplied by a scaling factor to estimate annual consumption of dreissenid mussels by lake whitefish for the entire lake. The scaling factor was equal to the total surface area of the lake divided by the surface area of all of the management units in the lake that were modeled for our study. Thus, we assumed that lake whitefish density in the management units used in this study was similar to that outside these management units. Comparison of commercial trap net catch per unit effort data between the management units included in our study and other areas of the lake indicated that this assumption was valid. For example, commercial trap net catch per unit effort in WFH-03, a management unit lacking an SCAA model, averaged $162 \pm 36 \mathrm{~kg}$ per lift $( \pm 95 \%$ confidence interval) during 1998-2005; this average was very similar to the mean of commercial trap net catch per unit effort of 164 $\pm 26 \mathrm{~kg}$ per lift obtained by pooling data for WFH-02 and WFH-04, which were management units with SCAA models, over the same time period (M.PE, unpublished data). Management unit WFH-03 was bordered by management unit WFH-02 on the north and by management unit WFH-04 on the south (Fig. 1). Scaling factors for Lakes Michigan and Huron were 2.5 and 1.9, respectively.

We estimated $95 \%$ confidence intervals about the lakewide annual consumption estimates by computing the mean of the $95 \%$ confidence interval half-width for population size (as derived from the SCAA model applications) divided by the population size across all combinations of management unit, lake whitefish age, and year. This mean quotient was then applied to the lakewide annual consumption estimate to estimate its 95\% confidence interval. Given that the bulk of the error in bioenergetics model estimates of lakewide consumption stems from error in estimating population size (Stewart et al., 1983), this approach was appropriate. Nevertheless, our estimates of the $95 \%$ confidence intervals represented conservative estimates of the error around our consumption estimates, because we did not take into account all of the sources of error associated with estimating annual consumption of dreissenid mussels by the lake whitefish populations. Further, our procedure to average relative errors across all combinations of management unit, lake whitefish age, and year to estimate the 95\% confidence interval around the lakewide annual consumption estimate for each lake was ad hoc.

We also calculated lakewide biomass of lake whitefish, by age, in Lake Michigan during 1998-2005 and Lake Huron during 2002-2004 by summing biomass across the management units for each combination of lake and age, and then multiplying the sum by the appropriate scaling factor. These lakewide biomass estimates repre- sented the average lakewide biomass, by age, in Lake Michigan during 1998-2005 and the average lakewide biomass, by age, in Lake Huron during 2002-2004. Analogously, we calculated lakewide annual consumption of dreissenid mussels by lake whitefish for each of the lake whitefish ages in Lake Michigan and in Lake Huron by summing annual consumption across the management units for each combination of lake and age and then multiplying the sum by the appropriate scaling factor.

\section{Results and discussion}

Population modeling results indicated that, for most ages, lakewide biomass of lake whitefish in Lake Huron was more than twice as high as lakewide biomass of lake whitefish in Lake Michigan (Fig. 2). Coupling the SCAA model estimates of the lake whitefish population parameters with the modified lake whitefish bioenergetics model revealed that lakewide annual consumption of dreissenid mussels was roughly five to ten times higher in Lake Huron than in Lake Michigan for each of the lake whitefish ages (Fig. 3).

Summing the lakewide annual consumption estimates across all ages for each of the lakes yielded annual consumption estimates of dreissenid mussels by lake whitefish populations in Lakes Michigan and Huron of 109 and 820 kt, respectively (Fig. 4). Thus, annual consumption of dreissenid mussels by the lake whitefish population in Lake Huron was nearly eight times greater than that for the Lake Michigan lake whitefish population. Reasons for the substantially higher consumption rate in Lake Huron compared with Lake Michigan were threefold. First, based on the SCAA model applications, the estimated lakewide biomass of age 3 and older lake whitefish in Lake Huron (129 kt) was 2.4 times greater than that in Lake Michigan (53 kt). Second, the proportion of dreissenid mussels in the diet of lake whitefish from Lake Huron (0.68) was higher than that in Lake Michigan (0.37). Third, specific consumption rates for Lake Huron lake

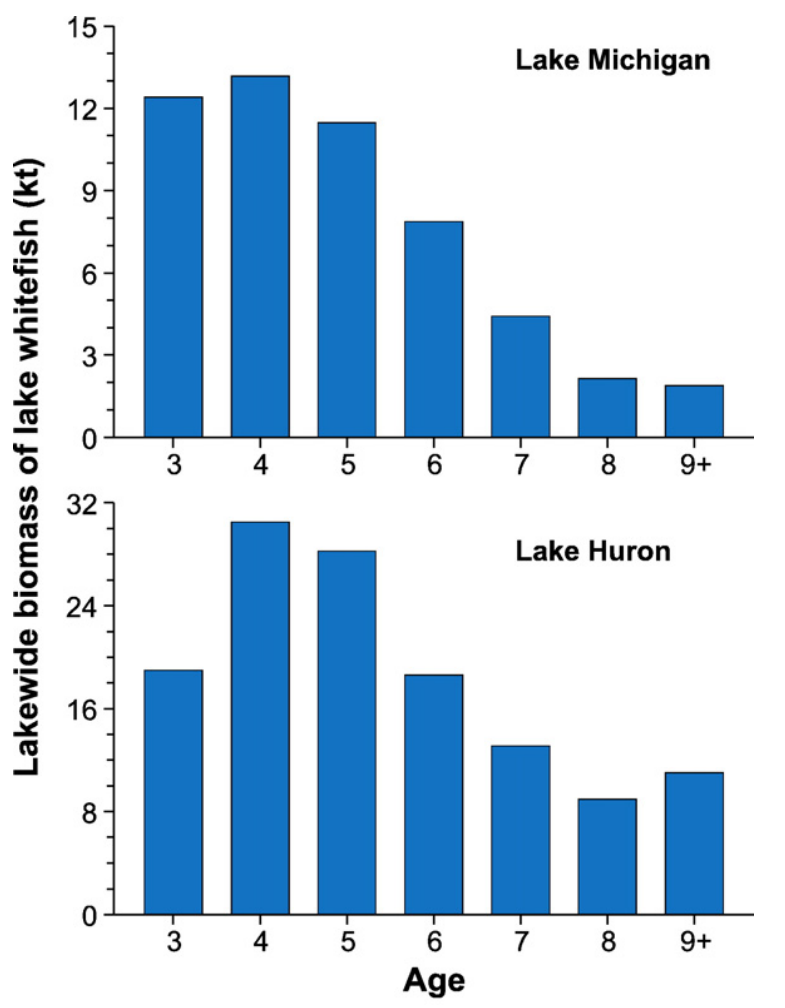

Fig. 2. Estimates of average lakewide biomass of lake whitefish in Lake Michigan during 1998-2005 and in Lake Huron during 2002-2004, by age, based on statistical catch-atage (SCAA) model applications. The $9+$ designation included all lake whitefish of age 9 and older. 


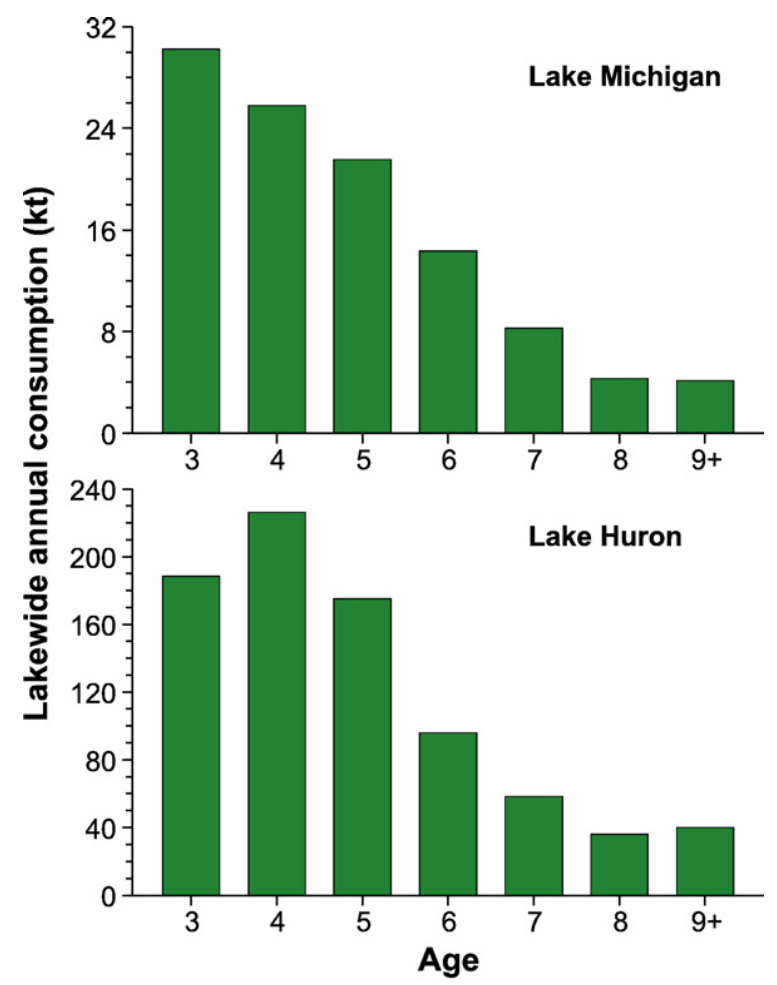

Fig. 3. Estimates of lakewide annual consumption of dreissenid mussels by lake whitefish in Lake Michigan during 1998-2005 and in Lake Huron during 2002-2004, by age. A lake whitefish bioenergetics model (Madenjian et al., 2006) was coupled with statistical catch-at-age (SCAA) models for lake whitefish populations (Ebener et al., 2005 ) to estimate lakewide annual consumption of dreissenid mussels in both lakes. The $9+$ designation included all lake whitefish of age 9 and older.

whitefish were substantially higher than those for Lake Michigan lake whitefish, owing to energy density of the diet of Lake Huron lake whitefish being less than that for Lake Michigan lake whitefish (Pothoven and Madenjian 2008).

We conclude that dreissenid mussels are not a "dead end" in Great Lakes food webs. Our estimates of annual consumption of driessenid mussels by lake whitefish populations in Lakes Michigan and Huron far exceeded the previously published estimate of annual consumption of dreissenid mussels by the round goby population in central Lake Erie. Given that the standing stock estimate of dreissenid mussels in Lake Huron during 2003 was comparable to the standing stock

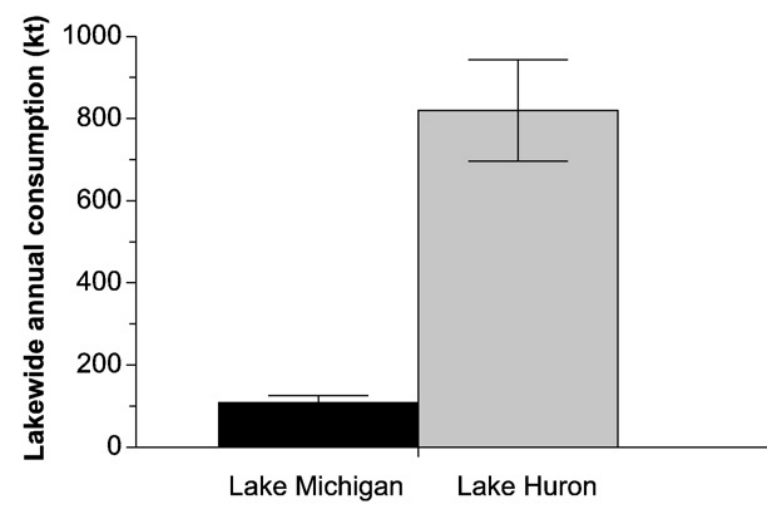

Fig. 4. Estimates of annual consumption of dreissenid mussels by the lake whitefish population (age 3 and older fish) in Lake Michigan during 1998-2005 and by the lake whitefish population (age 3 and older fish) in Lake Huron during 2002-2004. A lake whitefish bioenergetics model (Madenjian et al., 2006) was coupled with statistical catch-at-age (SCAA) models for lake whitefish populations (Ebener et al., 2005) to estimate lakewide annual consumption of dreissenid mussels in both lakes. In addition, 95\% confidence intervals were included for lake whitefish consumption estimates. estimate of dreissenid mussels in central Lake Erie during the early 2000s (Nalepa et al., 2009), the predation effect exerted by lake whitefish on dreissenid mussels in Lake Huron appeared to be far greater than the predation effect exerted by round gobies on dreissenid mussels in Lake Erie. Clearly, based on our bioenergetics model application, substantial amounts of energy flow from dreissenid mussels to lake whitefish populations in both Lake Michigan and Lake Huron each year.

Although predation on dreissenid mussels in the Great Lakes has been documented for diving ducks, freshwater drum (Aplodinotus grunniens), yellow perch (Perca flavescens), and round goby (French 1993; Morrison et al., 1997; Mitchell et al., 2000; Bunnell et al., 2005), our study was the first to elucidate a strong trophic link between dreissenid mussel populations and lake whitefish populations in the Great Lakes. To the best of our knowledge, the only previous estimate of annual consumption of dreissenid mussels by a predator population in the Great Lakes, on a basinwide or lakewide level, was the estimate of $6 \mathrm{kt}$ for round gobies feeding on dreissenid mussels in the central basin of Lake Erie by Bunnell et al. (2005). Our bioenergetics model estimates suggested that, on a lakewide level, lake whitefish was a more important predator on dreissenid mussels than round goby in the Great Lakes. Nevertheless, findings by Lederer et al. (2008) suggested that round goby predation on dreissenid mussels could have a significant effect on dreissenid mussel abundance in the littoral zone of Green Bay of Lake Michigan.

One plausible explanation for the faster rate of increase of the dreissenid mussel population size in Lake Michigan, compared with that in Lake Huron, would be that the substantially higher rate of predation by lake whitefish on dreissenid mussels in Lake Huron has slowed the dreissenid mussel population growth rate in Lake Huron. Both lakes were invaded by dreissenid mussels at the same time. Nalepa et al. (2009) calculated a dreissenid mussel population growth rate in Lake Huron during the 2000s of only $13 \%$ per year, in contrast to an estimated population growth rate of $45 \%$ per year in Lake Michigan during the 2000s. In 2005, dreissenid mussel density in Lake Michigan was estimated to be more than ten times higher than that in Lake Huron (Nalepa et al., 2009). We estimated that lake whitefish predation rate on dreissenid mussels in Lake Huron was about eight times higher than that in Lake Michigan.

To capture the dynamics of Great Lakes food webs, food web models will need to incorporate the dreissenid mussel-lake whitefish trophic link. To investigate the effects of dreissenid mussels and other recent invaders on Great Lakes ecosystems, development and exercising of food web models have been proposed ( $\mathrm{T}$. Johnson, Ontario Ministry of Natural Resources, Glenora Fisheries Station, 41 Fish Hatchery Lane, R.R.\#4, Picton, ON KOK 2TO, Canada, personal communication). Our findings have provided ample justification for inclusion of the dreissenid mussel-lake whitefish trophic link in these modeling efforts.

\section{Acknowledgments}

We thank S. Lozano, J. Savino, and graduate students and faculty at Michigan State University (All Things Wet group) for reviewing the manuscript and providing helpful comments for its improvement. We also thank C. Geddes for computing the surface area in each of the lake whitefish management units and the total surface areas for Lakes Michigan and Huron. This study was funded, in part, by the Great Lakes Fishery Trust. This article is Contribution 1539 of the USGS Great Lakes Science Center and contribution 1523 of the Great Lakes Environmental Research Laboratory.

\section{References}

Arney, D.C., Grubbs, J.H., 2001. Results of the 2001 interdisciplinary contest in modeling. UMAP J. 22, 355-366.

Bunnell, D.B., Johnson, T.B., Knight, C.T., 2005. The impact of introduced round gobies 
(Neogobius melanostomus) on phosphorus cycling in central Lake Erie. Can. J. Fish. Aquat. Sci. 62, 15-29.

Ebener, M.P., Bence, J.R., Newman, K.R., and Schneeberger, P.J., 2005. Application of statistical catch-at-age models to assess lake whitefish stocks in the 1836 treatyceded waters of the upper Great Lakes. In Proceedings of a Workshop on the Dynamics of Lake Whitefish (Coregonus clupeaformis) and the Amphipod Diporeia spp. in the Great Lakes. L. C. Mohr and T. F. Nalepa, eds., pp. 271-309. Ann Arbor, MI: Great Lakes Fishery Commission Technical Report 66.

Environment Canada and U. S. Environmental Protection Agency, 2003. State of the Great Lakes 2003. EPA 905-R-03-004.

French III, J.R.P., 1993. How well can fishes prey on zebra mussels in eastern North America? Fisheries 18 (6), 13-19.

Haynes, J.M., Stewart, T.W., Cook, G.E., 1999. Benthic macroinvertebrate communities in southwestern Lake Ontario following invasion of Dreissena: continuing change. J. Great Lakes Res. 25, 828-838.

Hecky, R.E., Smith, R.E.H., Barton, D.R., Guildford, S.J., Taylor, W.D., Charlton, M.N., Howell, T., 2004. The nearshore phosphorus shunt: a consequence of ecosystem engineering by dreissenids in the Laurentian Great Lakes. Can. J. Fish. Aquat. Sci. 61, $1285-1293$.

Johannsson, O.E., Dermott, R., Graham, D.M., Dahl, J.A., Millard, E.S., Myles, D.D., LeBlanc, J., 2000. Benthic and pelagic secondary production in Lake Erie after the invasion of Dreissena spp. with implications for fish production. J. Great Lakes Res. 26, 31-54.

Lederer, A.M., Janssen, J., Reed, T., Wolf, A., 2008. Impacts of introduced round goby (Apollonia melanostoma) on dreissenids (Dreissena polymorpha and Dreissena bugensis) and on macroinvertebrate community between 2003 and 2006 in the littoral zone of Green Bay, Lake Michigan. J. Great Lakes Res. 34, 690-697.
Madeniian, C.P., O'Connor, D.V., Pothoven, S.A., Schneeberger, P.J., Rediske, R.R., O'Keefe J.P., Bergstedt, R.A., Argyle, R.L., Brandt, S.B., 2006. Evaluation of a lake whitefish bioenergetics model. Trans. Am. Fish. Soc. 135, 61-75.

Mitchell, J.S., Bailey, R.C., Knapton, R.W., 2000. Effects of predation by fish and wintering ducks on dreissenid mussels at Nanticoke, Lake Erie. Ecoscience 7, 398-409.

Morrison, T.W., Lynch Jr., W.E., Dabrowski, K., 1997. Predation on zebra mussels by freshwater drum and yellow perch in western Lake Erie. J. Great Lakes Res. 23, 177-189.

Nalepa, T.F., Mohr, L.C., Henderson, B.A., Madenjian, C.P., and Schneeberger, P.J., 2005. Lake whitefish and Diporeia spp. in the Great Lakes: an overview. In Proceedings of a Workshop on the Dynamics of Lake Whitefish (Coregonus clupeaformis) and the Amphipod Diporeia spp. in the Great Lakes. L. C. Mohr and T. F. Nalepa, eds., pp. 3-19. Ann Arbor, MI: Great Lakes Fishery Commission Technical Report 66.

Nalepa, TF. Fanslow, D.L, Lang G.A. 2009. Transformation of the offshore benthic community in Lake Michigan: recent shift from the native amphipod Diporeia spp. to the invasive mussel Dreissena rostriformis bugensis. Freshw. Biol. 54, 466-479.

Pothoven, S.A., Madenjian, C.P., 2008. Changes in consumption by alewives and lake whitefish after dreissenid mussel invasions in Lake Michigan and Huron. N. Am. J. Fish. Manage. 28, 308-320.

Pothoven, S.A., Nalepa, T.F., Madenjian, C.P., Rediske, R.R., Schneeberger, P.J., He, J.X. 2006. Energy density of lake whitefish Coregonus clupeaformis in Lakes Huron and Michigan. Environ. Biol. Fish. 76, 151-158.

Stewart, DJ. Weininger, D. Rottiers, D.V., Edsall, T. A, 1983. An energetics model for lake trout, Salvelinus namaycush: application to the Lake Michigan population. Can. J. Fish. Aquat. Sci. 40, 681-698. 